J. AMER. Soc. HorT. SCI. 118(2):298-303. 1993.

\title{
Genetic Similarity Among Brassica oleracea L. Genotypes as Measured by Restriction Fragment Length Polymorphisms
}

\author{
James Nienhuis ${ }^{1}$ \\ Department of Horticulture, University of Wisconsin, Madison, WI 53706 \\ Mary K. Slocum ${ }^{2}$ \\ Department of Biology, University of Utah, Salt Lake City, UT 84112 \\ Dawn A. DeVos ${ }^{3}$ \\ Harris-Moran Seed Company, 100 Breen Road, San Juan Bautista, CA 95045 \\ Roger Muren ${ }^{4}$ \\ Sun Seeds, 8850 59th Avenue, NE, Brooks, OR 97305
}

\begin{abstract}
Additional index words. Brassica oleracea var. italica, B. oleracea var. botrytis, B. oleracea var. capitata, genetic distance, genetic similarity, algorithms, computer software, principal components, multidimensional scaling
\end{abstract}

\begin{abstract}
Genetic similarities were calculated among 89 Brassica oleracea L. genotypes, which included 62 broccolis (var. italica), 16 cauliflowers (var. botrytis), and 11 cabbages (var. capitata). These entries represented a wide range of commercially available germplasm, including open-pollinated cultivars, commercial hybrids, the inbred parents of several hybrid cultivars, and 27 entries that were provided as unknowns. Sixteen random genomic clones were used as probes in Southern hybridizations to detect restriction fragment length polymorphism (RFLP). From each of the random probes, an average of four polymorphic bands were classified as to their presence or absence for each genotype. The genetic similarity between ail pairs of genotypes was calculated. A multidimensional scaling (MDS) plot indicated that the broccoli, cauliflower, and cabbage groups were clustered with very little overlap. Within groups, genetic similarity corresponded to relationships based on available pedigree information. Comparison of banding patterns between hypothetical and actual hybrids was used to correctly identify the parents of several parenthybrid combinations. The RFLP pattern of a hybrid and one of the parents (female) were used to predict the genotype and identity of the other parent (male).
\end{abstract}

Knowledge of the relative genetic similarity among individuals or populations is useful in a breeding program because it permits organization of germplasm and provides more efficient sampling of genotypes. At the inception of a breeding program, knowledge of the genetic relationships among genotypes can be used to complement phenotypic information in the development of breeding populations. Ultimately, knowledge of the genetic similarity between genotypes can facilitate the choice of individuals to cross in hybrid combinations to optimize expression of heterosis (Godshalk et al., 1990; Moll et al., 1965; Smith et al., 1990).

At the molecular level, the genetic similarity between two individuals is a function of their base pair sequences. In lieu of direct sequence data, indirect measures of genotypic differences that reflect underlying base pair differences are commonly used. Information from pedigrees can be used to calculate the coefficient of parentage (r) among genotypes (Malecot, 1948). However, because of the assumption of no relationship among the original parents, $r$ is likely underestimated, to an unknown amount, relative to the true genetic similarity. Phenotypic information on quantitative and morphological characteristics can also be used to estimate genetic similarity (Goodman and Stuber, 1980;

Received for publication 27 Mar. 1992. Accepted for publication 15 Aug. 1992. Research conducted at Native Plants Inc, 417 Wakara Way, Salt Lake City, UT 84102. Use of trade names does not imply endorsement of the products named nor criticism of similar ones not named. The cost of publishing this paper was defrayed in part by the payment of page charges. Under postal regulations, this paper therefore must be hereby marked advertisement solely to indicate this fact.

${ }^{1}$ Assistant Professor.

${ }^{2}$ Research Assistant Professor.

${ }^{3}$ Research Director.

${ }^{4}$ Research Director
Martinez et al., 1983; Singh et al., 1991). However environmental effects, as well as genotype by environmental interactions, can result in the failure of the phenotype to accurately represent the genotype. Moreover, although differences among genotypes in phenotypic performance would suggest base pair differences, identical phenotypic performance does not preclude base pair differences.

Variation for morphological or biochemical markers, such as isozymes, can be used to measure genetic similarity among genotypes; however, precise evaluation of these markers may be confounded with environmental effects (Goodman and Stuber, 1980; Smith, 1984). RFLPs provide an opportunity to more precisely measure genetic differences among individuals compared to morphological or biochemical markers because they: 1) are generally abundant in populations of interest, 2) have no apparent affect on plant fitness per se, and 3) are not affected by the environment (Soller and Beckmann, 1983).

The taxonomy and origin of Brassica species has been investigated based on cytogenetic studies (Prakash and Hinata, 1980), chemotaxonomic studies (Vaughn, 1977), classical taxonomy (Grey, 1982, 1989; Vaughn, 1977), and molecular (RFLP) markers ( Song et al., 1988). In addition, Hu and Quiros (1991) recently identified random amplified polymorphic DNA (RAPD) markers that could discriminate within and between 14 broccoli and 12 cauliflower cultivars. The objectives of this research were 1) to analyze RFLP information to determine the genetic relationships among a sample of genotypes both within and among three of the cultivated Brassica oleracea L. subspecies, var.

Abbreviations: MDS, multidimensional scaling; RAPD, random amplified polymorphic DNA; RFLP, restriction fragment length polymorphisms. 
botytis (cauliflower), var. capitata (cabbage), and var. italica (broccoli), and 2) to determine if predicted banding patterns of hybrids could be useful in determining their pedigree (parents).

\section{Materials and Methods}

Germplasm. Eighty-nine B. oleracea cultivars representing a wide range of commercially available germplasm were selected for use in this study, including 62 broccolis, 16 cauliflowers, and 11 cabbages (Table 1). The germplasm was obtained by requesting seeds or lyophilized leaf material from public and private institutions involved in breeding of cole crops. Among the 89 entries, 27 were obtained from two seed companies as "unknowns" (entry numbers 10 through 36). For these "unknowns" no information was provided a priori regarding either their classification, e.g., broccoli, cauliflower, or cabbage, or of the genetic relationships among them.

Many of the entries were commercial hybrid cultivars. We grew the commercial seed lots of several hybrids, including entries 7, 37, 39, 41, and 43, in an unreplicated trial in Brooks, Ore., in 1987, with uniform spacing of $50 \mathrm{~cm}$ between plants. By identifying smaller "off-type" individuals within a row of otherwise uniform plants, we attempted to recover the female inbreds of these commercial hybrids. In the case of entry 43, 'Shogun', we grew several commercial hybrid seed lots and discovered two off-types, one of which had anthocyanin pigmentation. The possible female parent corresponding to a hybrid cultivar is indicated by "-P" and " $-\mathrm{H}$ " after the names, respectively (Table 1).

RFLP procedures. Entries 10 through 36 were supplied as bulk lyophilized leaf material harvested from six to 10 plants. For the remaining samples, about equivalent amounts of leaf material were collected from 10 to 12 plants. Plant DNA was isolated from lyophilized leaf tissue and a restriction endonuclease (Eco RI) was used to digest the crude DNA samples. The procedures for DNA isolation, restriction endonuclease digestion, electrophoresis, Southern blotting, hybridization, and autoradiography have been previously described (Slocum et al., 1990; Song et al., 1988).

A total of 16 random Brassica genomic clones containing low copy number inserts were individually hybridized to Eco RI digested total genomic DNA samples. The set of random genomic clones used as probes in this study included EW1G03, EW1D02, EW2D03, EW2A06, EW2A07, EW1D03, EW1F08, EW4A05, EW3D07, EW5F07, EW4G11, EW2B12, EW4G08, EW3C10, EW2E07, and EW1E04 (Pioneer Hi-Bred International, Johnston, Iowa). Frequently the probes hybridized to multiple restriction fragments within individual samples, which resulted in complex banding patterns. For each hybridization combination, different size restriction fragments across all genotypes were assigned numbers $(1,2,3, \ldots \mathrm{n})$ according to decreasing molecular weights. From one to seven bands, which were polymorphic among this sample of genotypes, were scored for each of the 16 probes resulting in a total of 61 scored fragments. Each polymorphic fragment was treated as a unit character, and the genotype was scored for the presence or absence of a fragment.

Calculatinggenetic relationship. Genotypes were coded 1 for presence or 0 for absence of a band (Hill, 1987). Genetic similarities were calculated between pairs of genotypes based on the method developed by Nei and Li (1979), i.e., $D(X Y)=$ $2 \mathrm{~N}(\mathrm{XY}) /[\mathrm{N}(\mathrm{X})+\mathrm{N}(\mathrm{Y})]$ where $\mathrm{D}(\mathrm{XY})$ is the measure of genetic similarity between a pair of genotypes, $\mathrm{N}(\mathrm{XY})$ is the number of bands common to genotypes $\mathrm{X}$ and $\mathrm{Y}$, and $\mathrm{N}(\mathrm{X}), \mathrm{N}(\mathrm{Y})$ is the number of bands for genotypes $\mathrm{X}$ and $\mathrm{Y}$, respectively. The resulting $89 \times 89$ triangular matrix of genetic similarity values is too lengthy to be presented here, but the data are available upon request from the senior author. The genetic similarity matrix was subjected to principal components and MDS analysis (Wilkinson, 1989).

Crossing algorithm. The following algorithm was used to predict the inheritance of RFLP fragments in hybrids: $1 \times 1$ $=1,1 \times 0=1$, and $0 \times 0=0$. The algorithm is interpreted as follows: if either parent has a fragment then that fragment will be observed in the Southern blot of their progeny, and only if both parents lacked a fragment will it be absent in their progeny (Quinn et al., 1987). The algorithm is predictive if the observed fragment represents a homozygous parent. If the fragment represents an allele of a heterozygous parent, then the probability of that allele being transmitted to any one progeny is $1 / 2$; however, if the Southern analysis is based on a pooled sample of DNA from several progeny, then the probability of that allele being observed is increased $\left(1-1 / 2^{n}\right.$, where $n=$ the number of progeny sampled). Thus, although heterozygosity in the parents can be a potential source of error in the algorithm, this error is minimized by sampling pooled leaf material from several individuals from each entry.

\section{Results}

Genetic similarity. The $89 \times 89$ matrix of genetic similarity measures was subjected to several multivariate analyses procedures. The first and second principal components (PC1 and PC2) accounted for $64.5 \%$ and $6.0 \%$ of the variance, respectively. MDS is a multivariate procedure that is related to principal components and factor analysis; however, MDS can usually fit an appropriate model in fewer dimensions than these other procedures (Wilkinson, 1989). The principal coordinate scatter plots for principal components and MDS analysis were similar in appearance; however, because it produced a clearer separation of entries in two dimensions, the MDS plot is presented (Fig. 1).

Inspection of the MDS plot indicated distinct clusters, with almost no overlap, among the three subspecies, italica (broccoli), botrytis (cauliflower), and capitata (cabbage) (Fig. 1). The mean genetic similarity between the broccolis and cauliflowers was greater, $(0.60 \pm 0.06)$, than the mean genetic similarity between either the broccolis or the cauliflowers compared to the cabbages, $0.57 \pm 0.07$ and $0.59 \pm 0.05$, respectively. The unknown entries 34,35 , and 36 were grouped with the var. capitata group and were therefore predicted to be cabbages. Entries 32 and 33, also representing unknown genotypes, were grouped with the var. botrytis group and were predicted to be cauliflowers. All other unknowns (entries 10 through entry 31) were grouped with the var. italica group, and were predicted to be broccolis. Similar predictions of subspecies classifications were obtained using discriminate analysis (not shown). All predictions of subspecies classification of unknowns were confirmed as accurate by the providers of the source material.

The only genotype known to be an intermediate between subspecies is 'Floccoli', a home garden cultivar, sold as a curiosity, which is a hybrid between broccoli and cauliflower. The mean genetic similarities between 'Floccoli' and the broccoli entries and between 'Floccoli' and the cauliflower entries were 0.62 \pm 0.06 and $0.71 \pm 0.07$, respectively. The hybrid origin of 'Floccoli' (entry 68) is further indicated by it's position in the scatter plot near the var. botrytis group and var. italica groups (Fig. 1). Similarly, 'B-21' is a disease resistant cabbage derived from an interspecific hybrid between B. napus L. and B. oler- 
Table 1. Cultivars included in the analysis of RFLP data.

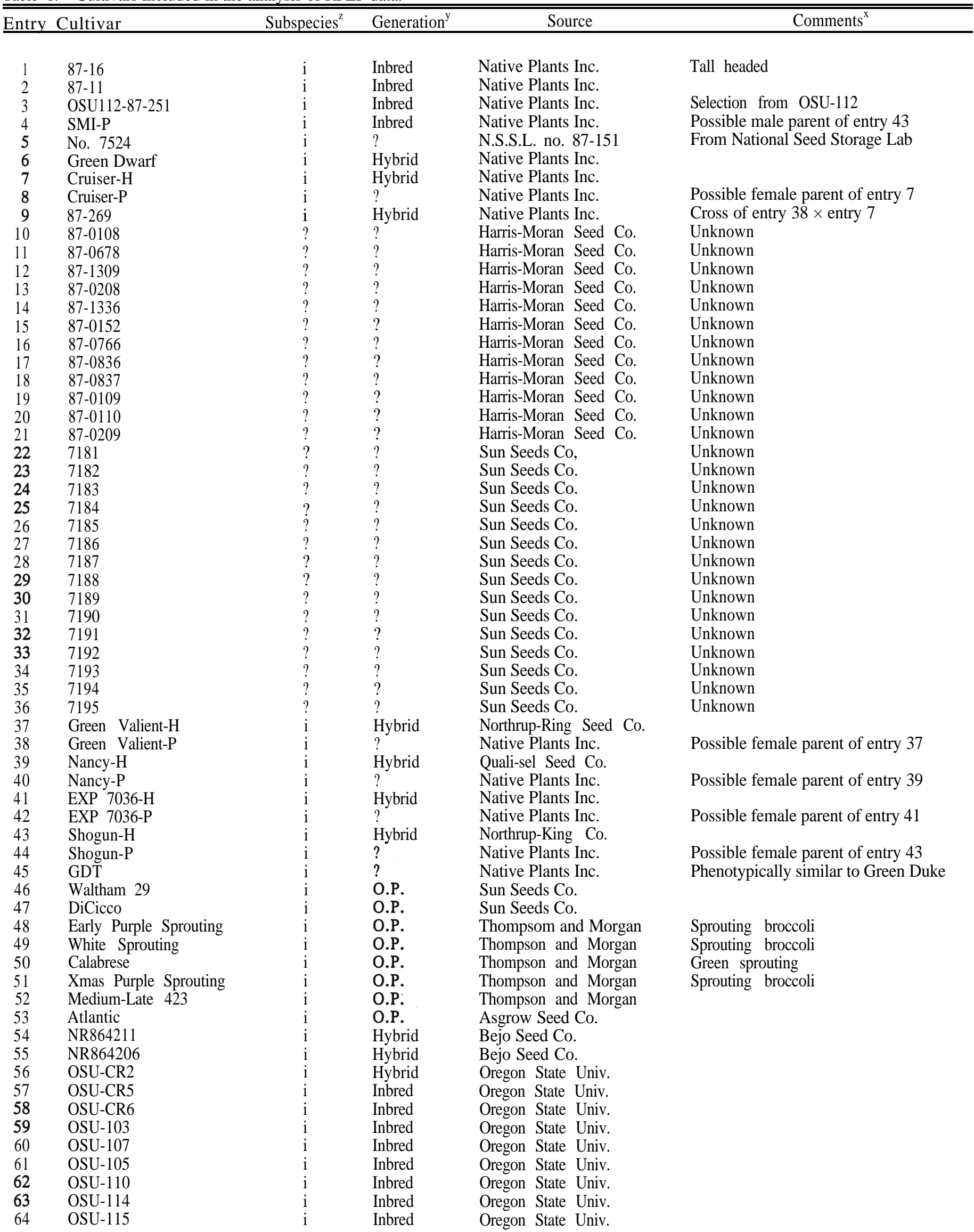


Table 1. continued.

\begin{tabular}{|c|c|c|c|c|c|}
\hline Entry & Cultivar & Subspecies $^{\mathrm{Z}}$ & Generation $^{y}$ & Source & Comments $^{\mathrm{x}}$ \\
\hline 65 & Hanamori & $\mathrm{i}$ & $\mathrm{H} \mathrm{y} \mathrm{b} \mathrm{r} \mathrm{i} \mathrm{d}$ & Kyowa Seed Co. & \\
\hline 66 & Tendan & $\mathrm{i}$ & Hybrid & Kyowa Seed Co. & \\
\hline 67 & Shgemore & $\mathrm{i}$ & Hybrid & Kyowa Seed Co. & \\
\hline 68 & Floccoli & $i-b$ & O.P. & Thompson and Morgan & Broccoli-Cauliflower hybrid \\
\hline 69 & Xmas White & $\mathrm{b}$ & $?$ & Sakata Seed Co. & \\
\hline 70 & Kangaroo & $\mathrm{b}$ & $?$ & $?$ & Australian type (?) \\
\hline 71 & Alert & b & $?$ & $?$ & Denmark (?) \\
\hline 72 & White Summer & b & $?$ & $?$ & Holland (?) \\
\hline 73 & Snowball Y Improved & b & O.P. & Peto Seed Co. & \\
\hline 74 & Snowflower & b & O.P. & Asgrow Seed Co. & \\
\hline 75 & Early White & b & Hybrid & Burpee Seed Co. & \\
\hline 76 & Burpeeana & b & O.P. & Burpee Seed Co. & \\
\hline 77 & Piracicaba Precose & b & O.P. & Bioplanta (Brazil) & Summer type \\
\hline 78 & Tetezopolis Precose & b & O.P. & Bioplanta (Brazil) & Summer type \\
\hline 79 & Terezopolis Gigante & b & O.P. & Bioplanta (Brazil) & Summer type (large curd) \\
\hline 80 & Alpha Durato & $\mathrm{b}$ & O.P. & Royal Sluis Seed Co. & \\
\hline 81 & Torina & $\mathrm{b}$ & O.P. & Bejo Seed Co. & \\
\hline 82 & B21 & C & O.P. & Agriculture Canada & Club Root Resistance \\
\hline 83 & iced \#41 & $\mathrm{C}$ & Inbred & native Plants $1 \%$. & Male parent of entry 85 \\
\hline 84 & Red \#41 & C & Inbred & Native Plants Inc. & Female parent of entry 85 \\
\hline 85 & Red \#41 & C & Hybrid & Native Plants Inc. & Hybrid of entry $83 \times$ entry 84 \\
\hline 86 & White \#49 & C & Inbred & Native Plants Inc. & Female parent of entry 88 \\
\hline 87 & White \#49 & C & Inbred & Native Plants Inc. & Male parent of entry 88 \\
\hline 88 & White \#49 & C & Hybrid & Native Plants Inc. & Hybrid of entry $86 \times$ entry 87 \\
\hline 89 & Earliana & $\mathrm{C}$ & O.P. & Burpee Seed Co. & \\
\hline
\end{tabular}

$\mathrm{z}_{\mathrm{i}}=$ Brasscia oleracea var. italica (broccoli), $\mathrm{b}=$ var. botrylis (cauliflower), $\mathrm{c}=$ var. capitata (cabbage), and ? = classification was unknown at the beginning of the study.

${ }^{\mathrm{y}}$ O.P. $=$ open pollinated.

${ }^{\mathrm{x}}$ Unknown: no information provided by supplier about classification or the genetic relationships.

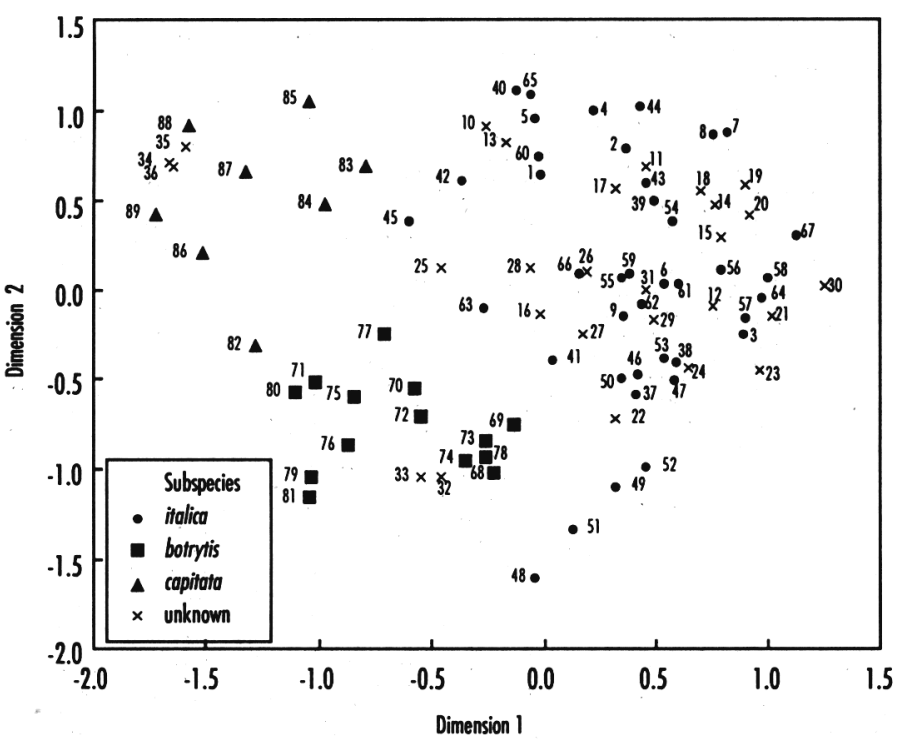

Fig. 1. Plot of first and second dimensions of MDS analysis of genetic similarity matrix of Brassica oleracea genotypes. Genotypes are listed in Table 1.

acea var. capitata (Chaing et al., 1977). The introgression of exotic genes into 'B-21' (entry 82) is suggested by its position on the scatter plot as an outlier in the var. capitata cluster, intermediate between that and the var. botrytis cluster.

The var. italica (broccoli) entries did not reveal any independent clusters. Nevertheless, entries known by pedigree to be closely related were located in close proximity to one another. For ex- ample, entries 48 and 51 are purple, and 49 and 52 white, cultivars of biennial sprouting broccoli, which is a type adapted to overwinter under Northern European climatic conditions and flower in the spring (Grey, 1989). These four sprouting broccolis were located in close proximity on the MDS plot and were apart from the other broccolis (Fig. 1). 'Waltham 29', 'DiCicco', and 'Atlantic' (entries 46, 47, and 53, respectively) are vintage open-pollinated cultivars of broccoli. These vintage cultivars were grouped in close proximity to one another and to 'Calabrese' (entry 50). 'Calabrese' was first cultivar introduced. into the United States by Italian immigrants and has been developed by breeding to have a more annual habit and heading form (Grey, 1989). The relationships on the MDS plot would suggest that the vintage broccoli cultivars are closely related to 'Calabrese' and may have been selected from it. In addition, a modem hybrid cultivar 'Green Valient' (entry 37) is located in close proximity to both the the vintage broccoli cultivars and 'Calabrese'. In contrast, the modem hybrid cultivar 'Shogun' (entry 43), its possible female and male parents (entries 44 and 4, respectively), hybrid cultivar 'Cruiser', (entry 7), and the cultivar 'Hanemori' (entry 65) appear to represent a distinct grouping of germplasm compared to the group that includes the vintage broccoli cultivars, 'Calabrese' and 'Green Valient'. Genotypes provided by Oregon State Univ. (entries 56 through 64) are all grouped in close proximity, except for entries 60 and 63, which were intermediate between the two germplasm groups identified above.

Two unknown entries, 23 and 24, and entry 38, the possible female parent of the modern hybrid cultivar 'Green Valient' (entry 37), are located in close proximity on the MDS plot (Fig. 1). The genetic similarities between entry 38 and entries 23 and 24 are 0.918 and 0.950 , respectively. We subsequently learned 
that entries 23 and 24 were developed by pedigree selection from an individual plant identified as the possible female parent of hybrid '7181' (entry 22). The results of these analyses would suggest that the hybrid cultivars 'Green Valient' and '7181' may share a closely related female parent. In addition, '7184' (entry 25 ) is a doubled haploid (DH) line derived from anther culture of hybrid '7181'. The genetic similarity between '7184' and '7181' is 0.720 . An additional DH line is ' 7186 ' (entry 27) that was derived from a broccoli hybrid '7187' (entry 28); the genetic similarity between these genotypes is 0.765 .

The var. botrytis (cauliflower) entries alone did not reveal any distinct groups (Fig. 1). Entries 77, 78, and 79, all of which are Brazilian cultivars adapted to tropical environments, did not form a distinct group. The only hybrid cauliflower, 'Early White' (entry 75), was located near the center of the cauliflower cluster.

Determination of parents of F1 hybrids. At the onset of this study, the only known parental-F1 hybrid relationships were one broccoli and two cabbages (comparisons 1,2, and 3, respectively, in Table 2). The inbred parents of the broccoli hybrid, entries 38 and 5, were crossed using the crossing algorithm (described in the materials and methods section), and the genetic similarity between the actual and the predicted hybrid banding pattern was 0.918 . In contrast, the genetic similarity between the actual and predicted hybrid banding patterns in both cabbages was 0.836 . In the cabbage hybrids, the genetic similarity between one of the parents (parent 'A') and the actual hybrid was greater $(0.935)$ than the genetic similarity between the parents $(0.885$ and 0.820 , respectively). A similar relationship was observed among the parents and F1 hybrid of the cabbage entries originally provided as unknowns by Sun Seeds (comparison 4). The observed genetic relationships among the parents and their F1 hybrid progeny suggests that the hybrid cabbages used in this study were contaminated with selfed seed of their female parents.

Random hybrid combinations were tested from among the entries to identify possible combinations of parents and hybrids. All entries provided as unknowns were crossed, and the resulting hybrid patterns were compared to the existing database entries. Among the unknowns provided by Sun Seeds, entry 26 was predicted to be a hybrid (0.967), with entries 25 and 30 as parents (comparison 5, Table 2). Similarly, entry 29 was predicted to be a hybrid (0.934), with entries 28 and 31 as parents (comparison 6, Table 2). These predictions were later confirmed as accurate by Sun Seeds. In contrast, although several parenthybrid combinations were among the unknowns sent by Harris-
Moran Seed Co. (comparisons 7, 8, and 9, in Table 2), the genetic similarity between actual and predicted hybrids was low, ranging from 0.717 to 0.850 .

Determination of male parent, given the hybrid and the female parent. Entries 7, 37, 39, 41, and 43 are commercial F1 hybrid broccoli cultivars (Table 1). The likely female parents of these hybrids were identified as off-types in uniform trials. The same algorithm used to predict hybrids from crosses between parents was used to predict the likely male parent of a hybrid combination, given the hybrid and the female parent. Entries 43 and 44 represent the commercial hybrid 'Shogun' and it's likely female parent, respectively. The predicted male parent of 'Shogun' is entry 4 (Table 3). Entry 4 is an off-type different from the female in that it possesses anthocyanin pigmentation on the stem. This prediction suggests that both the male and female parents of 'Shogun' are self incompatible, and that hybrid seed is harvested off both parents. Similarly, entry 37 and 38 represent the commercial broccoli hybrid 'Green Valient' and its likely female parent, respectively. The predicted male parent is entry 73, which is 'Snowball Y', a cauliflower. 'Green Valient' is not a broccoli $\times$ cauliflower hybrid; however, it is a modern hybrid characterized by small bead size. Cauliflower has been used by plant breeders as a source of genetic variance for bead size in broccoli (Grey, 1982); thus, the results here suggest that the male parent of 'Green Valient' has some cauliflower in its parentage.

\section{Discussion}

In these analyses and in the application of the crossing algorithm, the allelic relationships between bands was unknown; thus, we could not take advantage of the co-dominant information often available for RFLP data. Therefore, the individual bands are considered as dominant rather than co-dominant markers and provide information similar to that provided by RAPD markers. Thus, at a given locus, heterozygotes will have a banding pattern identical to one of the parents. Moreover, heterozygous individuals, either F1 hybrid or open pollinated, will likely have more bands coded as present than inbred genotypes. This difference can complicate the observed relationships between individual parents and their hybrid progeny, as heterozygous parents may appear as more closely related to their F1 hybrid progeny than the other more inbred parent. This deviation was observed in this experiment (Table 2); however, it did

Table 2. Genetic similarity between actual hybrids and hybrids predicted based on the inheritance of banding patterns between parents.

\begin{tabular}{|c|c|c|c|c|c|c|c|}
\hline \multirow[b]{3}{*}{$\begin{array}{c}\text { Comparison } \\
\text { (no.) }\end{array}$} & \multirow{2}{*}{\multicolumn{3}{|c|}{ Entry (no.) $)^{\mathrm{y}}$}} & \multicolumn{4}{|c|}{ Genetic similarity $^{2}$ between } \\
\hline & & & & \multirow[b]{2}{*}{$\begin{array}{l}\text { Predicted and } \\
\text { actual hybrid }\end{array}$} & \multirow[b]{2}{*}{ Parents } & \multirow{2}{*}{$\begin{array}{c}\text { Parent 'A' } \\
\text { and } \\
\text { actual hybrid }\end{array}$} & \multirow{2}{*}{$\begin{array}{c}\text { Parent 'B' } \\
\text { and } \\
\text { actual hybrid }\end{array}$} \\
\hline & A & $\mathrm{B}^{*}$ & Hybrid & & & & \\
\hline 1 & 38 & 5 & 9 & 0.918 & 0.557 & 0.787 & 0.541 \\
\hline 2 & 83 & 84 & 85 & 0.836 & 0.885 & 0.935 & 0.951 \\
\hline 3 & 86 & 87 & 88 & 0.836 & 0.820 & 0.935 & 0.885 \\
\hline 4 & 34 & 35 & 36 & 0.869 & 0.836 & 0.951 & 0.885 \\
\hline 5 & 25 & 30 & 26 & 0.967 & 0.767 & 0.884 & 0.884 \\
\hline 6 & 28 & 31 & 29 & 0.934 & 0.767 & 0.850 & 0.918 \\
\hline 7 & 13 & 11 & 19 & 0.850 & 0.667 & 0.800 & 0.867 \\
\hline 8 & 10 & 12 & 20 & 0.717 & 0.684 & 0.767 & 0.917 \\
\hline 9 & 12 & 13 & 21 & 0.717 & 0.700 & 0.917 & $\begin{array}{l}0.784 \\
0.717\end{array}$ \\
\hline
\end{tabular}

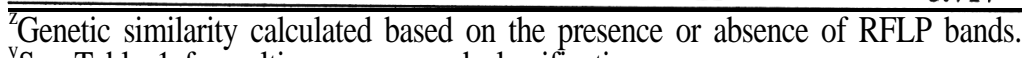

${ }^{\mathrm{y}}$ See Table 1 for cultivar names and classification.

xArbitrary designation of the parents of a hybrid. 
Table 3. The predicted male parent of a hybrid cultivar based on RFLP genotypes of the hybrid and the likely female parent.

\begin{tabular}{|c|c|c|c|c|c|}
\hline \multirow[b]{3}{*}{$\begin{array}{c}\text { Comparison } \\
\text { (no.) }\end{array}$} & & & \multirow{3}{*}{$\begin{array}{l}\text { Predicted } \\
\text { male } \\
\text { parent }\end{array}$} & \multicolumn{2}{|c|}{ Genetic similarity between } \\
\hline & \multicolumn{2}{|c|}{ Entry (no.) } & & \multirow[b]{2}{*}{ Parents } & \multirow{2}{*}{$\begin{array}{l}\text { Actual hybrid and } \\
\text { hybrid made using } \\
\text { predicted male parent }\end{array}$} \\
\hline & Hybrid & $\begin{array}{c}\text { Female } \\
\text { parent }\end{array}$ & & & \\
\hline 1 & 43 & 44 & 4 & 0.784 & 0.934 \\
\hline 2 & 37 & 38 & 73 & 0.705 & 0.867 \\
\hline 3 & 7 & 8 & 59 & 0.734 & 0.884 \\
\hline 4 & 39 & 40 & 11 & 0.771 & 0.935 \\
\hline 5 & 41 & 42 & 31 & 0.684 & 0.850 \\
\hline
\end{tabular}

"The likely female parent was identified as an "off-type" in a row of plants from a commercial $\mathrm{F}_{1}$ hybrid seed lot.

${ }^{\mathrm{y}}$ See Table 1 for cultivar names and classification.

not preclude the ability to identity the parents of most of the hybrid cultivars.

The reasons for the contrasting results in prediction of parental F1 hybrid combinations between the unknowns provided by Sun Seeds and those provided by Harris-Moran were unknown. We later learned that some of the parents used in the hybrids provided by Sun Seeds were highly inbred and, in fact, entries 28 and 25 were DH lines. In contrast, the parents of the hybrids provided by Harris-Moran Seed Co. were early generation (F3 and F4 ) developed by pedigree selection. Thus, the higher levels of heterozygosty in the parents of the hybrids provided by Harris-Moran Seed compared to those provided by Sun Seeds might account for the differences observed in prediction of parental F1 hybrid combinations. Determination of the level of heterozygosity in an inbred parent population is possible using RFLPs, and such data would help to resolve the sometimes unexpected relationships observed in this study between parents and hybrids. In addition, analysis of individuals rather than a bulk would permit determination of the percentage of contamination of selfed seed in the cabbage hybrids. Genetic marker data on many individuals might be more economically obtained by using diagnostic isozymes (Arus et al., 1982) rather than RFLPs. However, a limitation of isozymes is the lack of observed polymorphism among closely related genotypes compared to DNA-based markers, such as RFLPs or RAPDs (Hu and Quiros, 1991).

Only limited pedigree information is available for the 89 entries included in this experiment; nevertheless, the available pedigree information, including information available a priori and a posteriori, was highly correlated with genetic similarity as measured by RFLP polymorphisms. The information contributed by 61 RFLP bands provided a level of resolution of genetic relationships among cultivars and between parents and hybrids that might previously have been considered protected as "trade secrets" by plant breeding companies. Implied in these analyses, especially those dealing with the identification of parents of F1 hybrids, is the ability to dissect hybrid cultivars and better understand how both the individual parents and their hybrid are related to known germplasm resources. Moreover, by using RFLP information it is possible to identify one or more of the parents used in a F1 hybrid cultivar.

Plant breeders can use the RFLP information to organize genetic resources into related groups to make more informed decisions in the choice of parents. Eventually, the hypothetical banding patterns of test hybrids might be correlated with phenotypic information to predict both performance and adaptation of experimental hybrids. Moreover, the recent studies indicating a high correlation between RFLP-based genetic distance and single cross grain yield performance (Godshalk et al., 1990; Smith et al., 1990) suggest that molecular marker information can be used to identify parents with high heterotic potential.

\section{Literature Cited}

Arus, P., S.D. Tanskley, T.J. Orton, and K.A. Jones. 1982. Electrophoretic variation as a tool for determining seed purity and for breeding hybrid varieties of Brassica oleracea. Euphytica 31:417-428.

Chaing, M.S., B.Y. Chaing, and W.F. Grant. 1977. Transfer of resistance to race 2 of Plasmodiophora brassicae from Brassica napus to cabbage (B. oleraea var. capitata). I. Interspecific hybridization between B. napus and $B$. oleracea var. capitata. Euphytica 26:319-336.

Godshalk, E.B., M. Lee, and K.R. Lampkey. 1990. Relationship of restriction fragment length polymorphisms to single-cross hybrid performance on maize. Theor. Applied Genet. 80:273-280.

Goodman, M.M. and C.W. Stuber. 1980. Genetic identification of lines and crosses using isoenzyme electrophoresis. Proc. 35th Annu. Corn, Sorghum Res. Conf. 35:10-31.

Grey, A.R. 1982. Taxonomy and evolution of broccoli (Brassica oleracea var. italica). Econ. Bot. 36:397-410.

Grey, A.R. 1989. Taxonomy and evolution of broccolis and cauliflowers. Baileya $23 \cdot 28-46$.

Hill, W.G. 1987. DNA fingerprints applied to animal and bird populations. Nature 327:98-99.

Hu, J. and C.F. Quiros. 1991. Identification of broccoli and cauliflower cultivars with RAPD markers. Plant Cell Rpt. 10:505-511.

Malecot, G. 1948. Les mathematiques de l'heredité. Masson et Cie, Paris

Martinez, O.J., M.M. Goodman, and D.H. Timothy. 1983. Measuring racial differentiation in maize using multivariate similarity measures standardized by variation in F2 populations. Crop Sci. 23:775-781.

Moll, R.H., J.H. Lonnquist, J.V. Fortuna, and C.E. Johnson. 1965. The relationship of heterosis and genetic divergence in maize. Genetics 52:139-44.

Nei, M. and W. Li. 1979. Mathematical model for studying genetic variation in terms of restriction endonucleases. Proc. Natl. Acad. Sci. 76:5256-73.

Prakash, H. and K. Hinata. 1980. Taxonomy, cytogenetics and origin of crop Brassica, a review. Opera Bot. 55:1-57.

Quinn, T.W., J.S. Quinn, F. Cooke, and B.N. White. 1987. DNA marker analysis detect multiple maternity and paternity in single broods of the lesser snow goose. Nature 326:392-394.

Singh, S.P., J.A. Gutierrez, A. Molina, C. Urrea, and P. Gepts. 1991. Genetic diversity in cultivated common bean: II. Marker-based analysis of morphological and agronomic traits. Crop. Sci. 31:23-29.

Slocum, M.K., S.S. Figdore, W.E. Kennard, J.Y. Suzuki, and T.C. Osborn. 1990. Linkage arrangement of restriction fragment length polymorphism loci in B. oleracea. Theor. Applied Genet. 80:57-64

Smith, J.S.C. 1984. Geneticvariability within U.S. hybrid maize: Multivariate analysis of isozyme data. Crop Sci. 24:1041-1046.

Smith, O.S., J.S.C. Smith, S.L. Bowen, R.A. Tenborg, and S.J. Wall. 1990. Similarities among a group of elite maize inbreds as measured by pedigree, $\mathrm{F} 1$ grain yield, grain yield, heterosis, and RFLPs. Theor. Applied Genet. 80:833-840.

Soller, M. and J.S. Beckmann. 1983. Genetic polymorphism in varietal identification and genetic improvement. Theor. Applied Genet. 67:25-33.

Song, K.M., T.C. Osborne, and P.H. Williams, 1988. Brassica taxonomy based on nuclear restriction fragment length polymorphisms (RFLPS). 2. Preliminary analysis of subspecies within R. rapa (syn. campestris) and B. oleracea. Theor. Applied Genet. 76:593-600.

Vaughn, J.G. 1977. A multidisciplinary study of the taxonomy and origin of Brassica crops. Bioscience 27:35-40.

Wilkinson, L. 1989. SYSTAT: The System for Statistics. SYSTAT, Evanston, Ill. 